\title{
Clinical Study of Benign Breast Diseases Based on Aberrations in Normal Development and Involution Classification and Development
}

\author{
Archana Chilakala ${ }^{1}$, K. C. N. Navya ${ }^{2}$ \\ ${ }^{1}$ Assistant Professor, Department of General Surgery, Sri Venkateswara Medical College (SVMC) and SVRRGGH (RUIA), \\ Tirupati, Andhra Pradesh, India. \\ 2Postgraduate Student, Department of General Surgery, Sri Venkateswara Medical College (SVMC) and SVRRGGH (RUIA), \\ Tirupati, Andhra Pradesh, India.
}

\section{ABSTRACT}

\section{BACKGROUND}

Benign breast diseases are common disorders, with up to $30 \%$ of women suffering from benign breast diseases requiring treatment at point of time in their lives. ${ }^{1}$ The concept of ANDI (Aberrations of Normal Development and Involution) is recommended as a framework for understanding majority of benign conditions. Breast complaints are one of the most common reasons for surgical consultation. The majority, ultimately prove to have a benign origin. ${ }^{2}$ Breast lesions may present with a variety of symptoms often confusing clinical evaluation, leading to error in treatment of essentially benign conditions. We wanted to assess the role of ANDI classification in the management of benign breast diseases. We also wanted to categorise benign breast diseases with reference to ANDI classification and assess the role of ANDI classification as a tool to select the mode of benign breast diseases.

\section{METHODS}

After Institutional Ethics Committee approval, a prospective study was done among 100 female patients who presented with complaints of benign breast diseases under ANDI classification. The study was conducted in Sri Venkateswara Ramnarain Ruia Government General Hospital, Tirupati, from November 2017 to October 2018. All female patients who attained menarche presenting with complaints of benign breast conditions under ANDI classification attending OPD/admitted as inpatients in the Department of General Surgery were included in the study. Patients with carcinoma breast, breast abscess and those who are not willing to give consent were excluded. Total number of benign breast diseases studied was 100 .

\section{RESULTS}

The most common benign breast disorder is fibroadenoma, accounting for about 60 cases $(60 \%)$, followed by cyclical mastalgia with nodularity which accounts for 30 $(30 \%)$ cases, incapacitating mastalgia accounting for 5 cases (5\%), duct ectasia for 3 (3\%) and giant fibroadenoma for 2 cases (2\%).

\section{CONCLUSIONS}

The most common presentation is lump in the breast, followed by pain in the breast. Majority of the benign breast diseases occur in younger age group followed by middle age group. Fibroadenoma and mastalgia were the most common disorders. Fibroadenoma usually presents as discrete lump in the breast but multiple lumps in one breast and lumps in both the breasts are also noticed. Benign breast diseases most commonly affect upper and outer quadrant of the breast. Fine Needle Aspiration Cytology and Ultrasonogram nearly confirmed all the cases. Surgery proved to be the best way to manage the cases of fibroadenoma and simple excision was the better procedure.

\section{KEY WORDS}

FNAC, Benign Breast Disease, Histopathology, Microdochectomy Corresponding Author:
Dr. Archana Chilakala, Assistant Professor, Department of General Surgery, S. V. Medical College and SVRRGG Hospital, Tirupati-517501, Andhra Pradesh, India. E-mail: archana.chilakala@gmail.com

DOI: $10.14260 / \mathrm{jemds} / 2019 / 538$

Financial or Other Competing Interests: None.

How to Cite This Article:

Chilakala A, Navya KCN. Clinical study of benign breast diseases based on aberrations in normal development and involution classification and development. J. Evolution Med. Dent. Sci. 2019;8(31):24672474, DOI: $10.14260 /$ jemds/2019/538

Submission 13-05-2019,

Peer Review 21-07-2019,

Acceptance 27-07-2019,

Published 05-08-2019. 


\section{BACKGROUND}

Mammary glands or breasts are a distinguishing feature of mammals ${ }^{3}$. From puberty to death the breast is subjected to constant physical and physiological changes that relate to menses, pregnancy, gestation, lactation and menopause under the control of numerous hormones. Benign breast diseases are common disorder, upto $30 \%$ of women will suffer from benign breast diseases requiring treatment at sometimes in their lives ${ }^{1}$. Growing public awareness have increased referrals to hospital clinics for breast symptoms and currently malignant to benign ratio of 1: 10 are being seen in breast clinic (Barclay et al 1991)4.The term benign breast disease, (BBD) encompasses a heterogenous clinical and pathological condition which ranges from inflammatory condition to benign neoplastic conditions. The concept of ANDI (Aberrations of Normal Development and Involution) as described by Prof. Hughes is recommended as a framework for understanding majority of benign conditions. Breast complaints are one of the most common reasons for surgical consultation. The majority ultimately prove to have a benign origin $^{2}$. Breast lesions may present with a variety of symptoms often confusing clinical evaluation leading to error in treatment of essentially benign conditions. This clinicopathological study of benign breast diseases which include 100 cases, where all possible attempts to study the various aspects of the diseases and its management have been made, excluding inflammatory breast diseases and carcinoma of breast. We wanted to assess the role of ANDI Classification in the management of benign breast diseases. We also wanted to Categorise benign breast diseases with reference to ANDI classification and assess the role of ANDI classification as a tool to select the mode of benign breast diseases.

\section{The Concept of ANDI}

The nomenclature of benign breast diseases is very confusing. ${ }^{5}$ This is because over the last century a variety of clinicians and pathologists has chosen to describe a mixture of physiological changes and diseases process according to variety of clinical, pathological and etiological terminology. 6 To sort out this confusion, and new system has been developed and described by the "Cardiff breast clinic" i.e., A comprehensive classification which puts all the processes of physiological changes, growth, development and involution into a single frame work called ANDI (Aberrations of Normal development and Involution). ${ }^{7}$ Apart from congenital anomalies and inflammatory conditions. The benign breast diseases consist of benign breast tumours such as fibroadenoma, fibrocystic change, sclerosing lesions, and papillary lesions. . $^{4,9}$ Epithelial proliferative disease and rarely miscellaneous section ${ }^{10}$. Epithelial hyperplasias and papillomas are regarded as more complex conditions, which may have an association with cyclical and involutional changes. ${ }^{11,12}$

\section{Clinical Features of Benign Breast Disease}

Benign Breast disease generally presents as the lump, breast pain, nipple discharge and breast enlargement.

Lump- This is most common presenting complaint. ${ }^{13}$ Two main conditions responsible for discrete lump in breast are fibroadenoma in young women and cyst in peri or postmenopausal women, other causes of lump are phyllodes tumour, galactocele, fat necrosis, chronic abscess and skin and vascular lesions elsewhere in the body.14,15 In fibrocystic disease, there may be past history of similar complaint. In some cases, because these changes are prone for recurrence.16,17 Galactocele generally associated with recent or past history of lactation. ${ }^{2}$ In fat necrosis history of trauma is not always evident, sometimes it may be unrecognized. ${ }^{18}$ On palpation fibroadenoma appreciated as discrete lump with firm consistency and they move freely with in the breast tissue (Breast mouse). ${ }^{19}$ Cystic diseases are not always cystic in consistency because of their tense nature. Cysts are also mobile but not to the extent of fibroadenoma. ${ }^{20}$ The striking feature of phyllodes tumour is its large size with stretched shiny overlying skin. ${ }^{21}$ Skin may be warm with prominent subcutaneous veins and some time with ulcerations due to pressure necrosis. Galactocele presents as lump in the central or peri areolar region with cystic consistency. ${ }^{22}$ Other skin and vascular lesions have presentation elsewhere in the skin.

\begin{tabular}{|c|c|c|c|}
\hline & Normal & Disorder & Disease \\
\hline \multirow[t]{4}{*}{$\begin{array}{l}\text { Early Reproductive } \\
\text { years (15-25 years) }\end{array}$} & $\begin{array}{c}\text { Lobular } \\
\text { development }\end{array}$ & Fibroadenoma & Giant fibroadenoma \\
\hline & $\begin{array}{c}\text { Stromal } \\
\text { development }\end{array}$ & $\begin{array}{l}\text { Adolescent } \\
\text { hypertrophy }\end{array}$ & Gigantomastia \\
\hline & Nipple eversion & Nipple inversion & Subareolar abscess \\
\hline & & & Mammary duct fistula \\
\hline \multirow[t]{3}{*}{$\begin{array}{c}\text { Late reproductive } \\
\text { years (26-35 years) }\end{array}$} & $\begin{array}{l}\text { Cyclical changes } \\
\text { of menstruation }\end{array}$ & Cyclical mastalgia & $\begin{array}{c}\text { Incapacitating } \\
\text { mastalgia }\end{array}$ \\
\hline & & Nodularity & \\
\hline & $\begin{array}{c}\text { Epithelial } \\
\text { hyperplasia of } \\
\text { pregnancy }\end{array}$ & $\begin{array}{l}\text { Bloody nipple } \\
\text { discharge }\end{array}$ & \\
\hline \multirow[t]{6}{*}{$\begin{array}{c}\text { Involution } \\
\text { (36-55 years) }\end{array}$} & Lobular involution & Macrocysts & \\
\hline & & Sclerosing lesions & \\
\hline & Duct involution & & \\
\hline & Dilation & Duct ectasia & Periductal mastitis \\
\hline & Sclerosis & Nipple retraction & \\
\hline & $\begin{array}{c}\text { Epithelial turn } \\
\text { over }\end{array}$ & $\begin{array}{c}\text { Epithelial } \\
\text { hyperplasia }\end{array}$ & $\begin{array}{c}\text { Epithelial hyperplasia } \\
\text { with atypia }\end{array}$ \\
\hline
\end{tabular}

Mastalgia- There are two distinct groups of patients with these symptoms. One group has symptoms that bear a definite relation to the menstrual cycle (Cyclical mastalgia). In the remainder there is no such correlation (Non-cyclical mastalgia). ${ }^{23}$ Non-cyclical mastalgia has recently been reclassified to distinguish pain in the breast from that originating in surrounding tissue such as the chestwall.24

Cyclical Mastalgia- This is most common type of breast pain with discomfort lasting for a varying period of time before menstruation 25 . It accounts for $67 \%$ of cases referred to dedicated mastalgia ${ }^{26}$. Median presenting age is about 35 years. The pain of cyclical mastalgia is frequently, but not always, bilateral and is usually located in the upper, outer quadrants.

Non-Cyclical Mastalgia- This is even less well defined than cyclical counterpart. It occurs in both pre and postmenopausal women, with a median age of presentation of 45 years, as well as having no close relation to the menstrual cycle. ${ }^{27}$ Non-cyclical mastalgia tends to be more chronic. ${ }^{28}$ Unilateral and located in the medial quadrants of the breast or the peri areolar regions. It is not associated with lumpiness to the same degree as cyclical mastalgia and the pain frequently described as "burning" or "dragging" rather than a heavy feeling. ${ }^{29}$ Up to $50 \%$ of patients with non-cyclical mastalgia 
have pain that arises not from the breast but from surrounding musculoskeletal structures. ${ }^{30}$

\section{Investigations}

1. Non- Interventional:
I. Mammography.
II. Ultrasound.
III. Doppler flow study. ${ }^{31}$

2. Interventional
I. FNAC.
II. Core needle biopsy/ Excisional biopsy.
III. Surgical biopsy.
IV. VAB (Vacuum assisted biopsy)
V. Ductography.
VI. Image guided needle biopsy.

In any patient who present with a breast lump or other symptoms the diagnosis should be made by combination of clinical assessment, radiological imaging and tissue sample taken for either cytological or histopathological analysis called as "Triple Assessment".

Mammography- The most commonly used breast imaging procedure is Mammography, defined as an X-ray examination of breast. ${ }^{32}$ The two major types of mammography are screening mammography and Diagnostic mammography. Screening mammography is used to detect unsuspected breast cancer in asymptomatic women ${ }^{32}$. Diagnostic mammography is used to evaluate breasts of patients with symptoms, such as a lump or nipple discharge. Mammography is also used to guide interventional procedures including pre biopsy needle localization, needle aspiration, core needle biopsy and ductography ${ }^{33}$. The screening mammography consists of two views- mediolateral oblique view is most effective single view because it includes greatest amount of breast tissue, all upper quadrant and axillary tail whereas craniocaudal view gives information about medial quadrants and better view because of possibility of greater compression ${ }^{34}$. Mammography can give its feature as masses and calcifications and also gives features which are important clues to their aetiology. A mass is defined as space occupying lesion that is seen on at least two Mammographic projections. Calcification is the deposition of calcium salts in tissues. Fibroadenoma Appears as round, oval, or lobulated mass with a circumscribed margin. They may be solitary or multiple. In older women, they tend to develop characteristic coarse calcifications. Mammographic features alone cannot distinguish between cystosarcoma phyllodes tumour and fibroadenoma. Features suspicious of carcinoma with in fibroadenoma are a large mass, indistinct margin and clustered calcifications. Intraductal Papilloma is difficult to identify unless a tiny rosette of calcification with a barely perceptible rim of soft tissue can be seen. A bulge in visible duct may suggest diagnosis. Lipoma appears as radiolucent and surrounded by a viable, thin, fibrous capsule. In fatty females with fatty breast it is difficult to determine whether it is lipoma or normal fat. Because the risk of malignancy in breast masses in young is low and relatively different composition of the breast in adolescents as compared to adults, mammography is not recommended for routine screening or routine imaging of breast masses in adolescents.

Xeromammography- It is identical to mammography except that it is recorded on xerographic plates rather than conventional transparency. The image produced is positive rather than negative.

Magnification Mammography- This technique enhances the sharpness of detail and increases diagnostic accuracy for breast cancer. The optimal magnification is 1.5 times life size. Margins of breast masses and the degree and specificity of micro calcifications are clearly defined.

Digital Mammography- This records the image electronically as a digitally format rather than directly on film. The image is kept in a computer and can be either displaced on a fluorescent monitor or transferred to hard copy. It has the advantage of image magnification on the display monitor to use computer aided diagnosis and teleradiography.

Ultrasonography- Ultrasound is particularly helpful in young women with dense breast in whom mammography is difficult to interpret and is differentiating cystic and solid masses. Masses that are smaller than $0.5-1 \mathrm{~cm}$ may not be visualized and masses in a fatty breast that is also difficult to visualize ${ }^{35}$. The importance of ultrasound lies in the resolution of equivocal mammography. Ultrasound is an excellent method of guiding some interventional procedures. Ultrasonography features suggesting benign features include absence of malignant findings: ellipsoid shape, echogenic pseudo-capsule (Circumscribed Margins) hyper-echogenicity; homogenous interval echoes and enhanced echoes digital to the masses. Malignant lesions have an irregular shape, indistinct margin, speculations, micro calcifications, height greater than width, hypo-echogenicity and shadowing.

Doppler Studies- This technique is too time consuming to be practical for routine use with duplex scanners, the lesion and surrounding tissues can be examined. Information about vascular anatomy is obtained, including the number of vessels and their arrangement and configuration as well as the anatomical relationships between vessels and the lesions. Blood flow in malignant lesions is enhanced ${ }^{36}$. The signals can be used to detect increased flow and may further distinguish benign from malignant lesions. Thermography and Transillumination, are not effective and no longer in use.

Nipple Discharge Examination- If there is nipple discharge, colour of discharge to be noted. In general, if the discharge appears clear or milky, yellow or green, cancer is unlikely.

FNAC- It's an outpatient procedure. It involves the use of fine needle ( 22 or 23 gauge) with a syringe to aspirate cells from a suspicious area, smearing them on a glass slide, fix and stain for cytological examination. ${ }^{10}$ However, specific histological diagnosis may be impossible because of the inability to maintain architectural patterns with aspirations ${ }^{37}$. Even if adequate specimen is obtained, a definitive diagnosis is not always possible, and it cannot differentiate in situ carcinoma from invasive breast carcinoma. ${ }^{38}$ 
Core-Needle Biopsy- The core needle biopsy is similar to FNAC but, the caliber of the needle used is bigger, it removes a small cylinder of tissue ${ }^{39}$. There are two special devices used for taking core biopsy, they are Mammotome and advanced breast biopsy instrument (ABBI).

Surgical Biopsy and Excisional Biopsy- In few cases, when FNAC or core needle biopsy is inconclusive, surgical biopsy may be needed to remove a bit of tissue or whole tissue for examination under microscope. ${ }^{1}$ When lump is $<1 \mathrm{~cm}$, excision biopsy is attempted because it serves as a therapeutic as well as diagnostic procedure. Sometimes surgeon may use a procedure called wire localization during an excision of small lump that is difficult to locate by touch.

VAB- VAB means vacuum assisted biopsy, it is a recent diagnostic and therapeutic procedure. After injecting local anaesthesia on the skin and subcutaneous tissue, a $0.5 \mathrm{~cm}$ incision is made over skin, Mammotome is held firmly on the lump and Mammotome is connected to vacuum pump it will remove tissue by pieces thus it can serve as diagnostic and therapeutic if the lump is small.

Image-Guided Needle Biopsy- This acts as an alternative to surgical biopsy for mammographically detected abnormalities. Needle biopsy of occult lesions can be guided by stereotactic mammography or ultrasonography.

Ductography (Galactography)- Ductography is the injection of contrast medium into the lactiferous ducts in an attempt to pre-operatively determine the nature, location and extent of lesions causing serous or bloody discharge. ${ }^{40}$

Procedure- The duct is gently dilated with a dilator. A small blunt canula is inserted under sterile conditions into nipple ampulla and with the patient in supine position 0.1-0.2 $\mathrm{ml}$ of dilute contrast agent is injected until patient experiences fullness, cranio caudal and medio-lateral Mammographic views are obtained without compression. ${ }^{41}$

- Intraductal Papillomas- Small filling defects surrounded by contrast agent.

- Cysts- May opacify when they communicate with ducts.

- Carcinomas- Irregular masses.

- Invasive Tumour- Multiple intraluminal filling defects.

\section{Treatment of Benign Breast Disease}

Management of Lump: In case of vague lump after examination of symmetrical are in the opposite breast, if that area also has lump simple reassurance and follow up is enough ${ }^{42}$. If there is no lumpiness in the opposite breast investigations like mammography, USG and FNAC are necessary for confirmation of diagnosis and then management depends upon the condition. ${ }^{2}$ If there is a dominant palpable mass, management depends upon the age of the patient. In the case where there is least suspicion of malignant, menstrual cycle is mandatory. If it resolves, clinical follow up for 3 months is enough. ${ }^{31}$ If the lump persists; investigations like USG, FNAC are necessary. Patient management depends upon the diagnosis arrived at by the above investigations. If the diagnosis is still inconclusive with the above investigations, surgical biopsy is necessary. In case of fibroadenoma excision is the standard treatment. Now a days due to better understanding of the natural history of fibroadenoma, many studies recommend the conservative management especially in young patients under 25 years, provided the cytological examination confirms the diagnosis, treatment for giant fibroadenoma and juvenile fibroadenoma is enucleation.

\section{METHODS}

The present study is a prospective study done on 100 female patients who presented with complaints of benign breast diseases under ANDI classification conducted in Sri Venkateswara Ramnarain Ruia Government General Hospital, Tirupati after Institutional Ethics Committee approval from November 2017 to October 2018. The patients were required to give written informed consent prior to enrolment in the study and clearance was taken as per institute's ethical committee guidelines.

\section{Inclusion Criteria}

All female patients who attained menarche presenting with complaints of benign breast conditions under ANDI classification attending Outpatient and Inpatient in the Department of General Surgery.

\section{Exclusion Criteria}

Patients with Carcinoma breast, breast abscess and those who are not willing to give consent.

\section{Methodology}

The study compromises 100 cases of benign breast diseases which includes 60 cases of Fibroadenoma, 30 Cyclical mastalgia with nodularity, 5 cases of Incapacitating Mastalgia, 3 cases of Duct ectasia and 2 cases of Giant Fibroadenoma from Outpatient and In-patient wards in the department of General surgery, Sri Venkateswara Ramnarain Ruia Government General Hospital, (SVRRGGH) Tirupathi. A detailed history is taken regarding lump, pain, nipple discharge, menstrual history, obstetric history, family history, previous surgery if the patients have undergone, history of oral contraceptive pills. General physical examination is done. A detailed local and systemic examination is carried out and clinical diagnosis is made. Patients are subjected to routine blood examination and specific investigations like FNAC, Ultrasonography of the breasts, Mammography. The excised specimens were sent for histopathological examination for confirmation of clinical diagnosis. After studying in detail about 100 cases, with regards to the age of the patient, presenting complaints, diagnostic investigations and treatment received, the most common and rare benign breast diseases are represented in the form of tables, graphs and charts to detect them early based on symptoms and to arrive at correct diagnosis without a delay on unnecessary investigations. Total number of benign breast diseases studied - 100 who attended outpatient during the study period. Sample size determination is based on confidence intervals. Statistical analysis was done by Statistical Proportion tests. 


\section{RESULTS}

The most common benign breast disorder is Fibroadenoma, accounting for about 60 cases $(60 \%)$, followed by cyclical mastalgia with nodularity which accounts for $30(30 \%)$ cases, incapacitating mastalgia accounting for 5 cases (5\%), duct ectasia for $3(3 \%)$ and giant fibroadenoma for 2 cases (2\%). The most common condition is Fibroadenoma which is either painless or very rarely painful to present with. It is followed by mastalgia either cyclical with nodularity or severe and incapacitating variant. In my study, the most commonly affected age group of benign breast disease is 20 to 30 years, 56 cases ( $56 \%)$, followed by 31 to 40 years, 27 cases $(27 \%)$. But the majority of the breast diseases showed their expression in the age groups of 31 to 40 years. The peak incidence of Fibroadenoma is 21 to 30 years age group with 42 cases $(42 \%)$ followed by 11 to 20 years with 15 cases $(15 \%)$. Cyclical mastalgia with nodularity is noted in its peak in 31 to 40 years of age group - 16 cases (16\%) Incapacitating mastalgia and Duct Ectasia are also noted in its peak in 31 to 40 years of age group - 5 cases (5\%) and 2 cases (2\%) respectively. Giant Fibroadenoma are predominantly found among age groups of 21 to 40 years In the study out of 60 cases of fibroadenoma, 32 cases presented with a history of 1 to 3 months, 26 cases presented with a history of 4 to 6 months and 2 cases with 7 to 9 months history. Out of 30 cases of Cyclical mastalgia with nodularity, 6 cases presented in 1 to 3 months, 16 cases in 4 to 6 months, and 8 cases in 7 to 9 months. Out of 5 cases of Incapacitating mastalgia 3 cases presented in 1 to 3 months and 2 cases presented in 4 to 6 months. Two cases of Duct ectasia presented in 4 to 6 months and one case in 1 to 3 months history. Two cases of Giant Fibroadenoma presented with 7 to 9 months history. In the present study, Fibroadenoma presented as painless lump in majority of cases (50\%), and as a painful lump in $10 \%$ of cases. Cyclical mastalgia with nodularity presented with pain in the breast with multiple nodules or lumps in the breast (30\%) and the same is with Incapacitating mastalgia but the pain tends to be more severe. Duct ectasia presents with painful lump and with nipple discharge in most of the cases. Gaint fibroadenoma like fibroadenoma mainly presented as a painless lump. In the present study, the majority of the fibroadenoma cases presented in the right breast 34\% followed by left breast $25 \%$ and in both the breasts in $1 \%$ of cases. The cases of Cyclical mastalgia with nodularity presented mainly in both the breasts (30\%) as it is same with Incapacitating Mastalgia (5\%). Duct ectasia mainly presented in the right breast $2 \%$ followed by left breast $1 \%$ of cases. Giant fibroadenoma was seen in only left breast in the present study. In cases of Fibroadenoma and Giant Fibroadenoma, the investigations done are Ultrasonogram and FNAC (Fine Needle Aspiration Cytology) and routine blood investigations they may need if surgery is planned. For Cyclical mastalgia with nodularity and Incapacitating mastalgia routinely Mammogram is done. For cases of Duct ectasia, Ultrasonogram and Cytology of the nipple discharge is done.

Out of 100 cases, 60 patients needed surgery and 40 patients were given medical management. In the present study, 56 cases of Fibroadenoma underwent surgery and 5 cases are managed medically. All the cases of Duct ectasia and Giant fibroadenoma were managed with Microdochectomy. All cases of incapacitating mastalgia and Cyclical mastalgia with nodularity responded well with medical management. This clearly shows not all the benign breast conditions need surgery.

\begin{tabular}{|c|c|c|c|c|c|c|}
\hline \multirow[t]{3}{*}{ Diseases } & \multirow{3}{*}{$\begin{array}{c}\text { Total } \\
\text { Number }\end{array}$} & \multicolumn{4}{|c|}{ Lump } & \multirow{2}{*}{$\begin{array}{c}\text { Nipple } \\
\text { Discharge }\end{array}$} \\
\hline & & \multicolumn{2}{|c|}{ Painless } & \multicolumn{2}{|c|}{ Painful } & \\
\hline & & No. & $\%$ & No. & $\%$ & \\
\hline Fibroadenoma & 60 & 50 & 50 & 10 & 10 & \\
\hline Cyclical mastalgia with nodularity & 30 & & & 30 & 30 & \\
\hline Incapacitating mastalgia & 5 & & & 5 & 5 & \\
\hline Duct ectasia & 3 & & & 3 & 3 & 3 \\
\hline Giant fibroadenoma & 2 & 2 & 2 & & & \\
\hline Total & 100 & & & & & \\
\hline Table 2.1 & Iode of Pre & sent & ion & & & \\
\hline
\end{tabular}

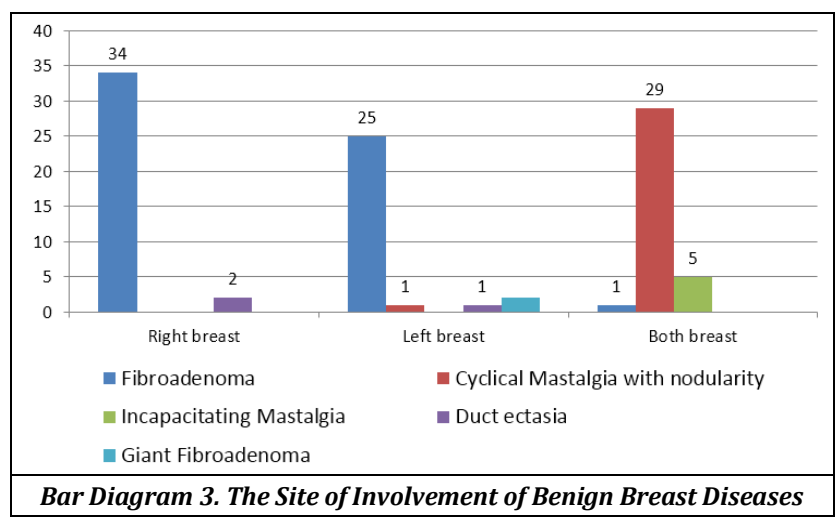

\begin{tabular}{|c|c|c|}
\hline Diagnosis & Surgical & Conservative \\
\hline Fibroadenoma & 55 & 5 \\
\hline Cyclical mastalgia with nodularity & & 30 \\
\hline Incapacitating mastalgia & & 3 \\
\hline Duct ectasia & 3 & \\
\hline Giant fibroadenoma & 2 & \\
\hline Table 4. Treatment of Benign Breast Diseases \\
\hline
\end{tabular}

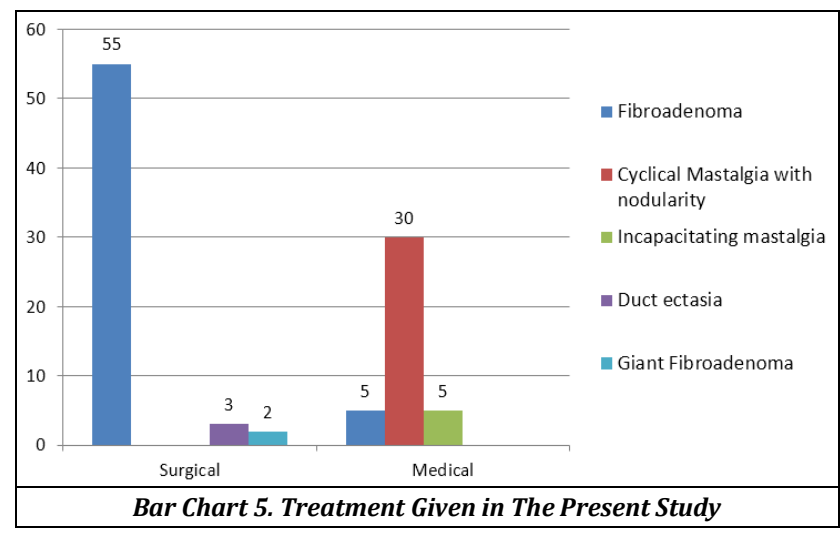

\section{DISCUSSION}

Benign breast disease is a common disease affecting the women from puberty to menopause. In the present study 100 women who presented with complaints of benign breast diseases in the Department of General surgery, were studied with clinical examination, radiological and pathological investigations.

\section{Sex Distribution}

In the present study 100 cases of benign breast diseases were studied in only female patients attending the Department of General surgery in SVRRGGH, Tirupathi. 


\section{Age Distribution}

In the present study of 100 cases, $15 \%$ of the cases were in the age group of 11 to 20 years. $56 \%$ of cases are in the age group of 21 to 30 years of age followed by $27 \%$ of cases in 31 to 40 years of age group. Only $2 \%$ of the cases are in 41 to 50 years of age group. The present study shows the most common age group is 21 to 30 years of age. It is similar to the study done by Sushila Khanna etal ${ }^{43}$ in which $40.06 \%$ of cases were in the age group of 21 to 30 years. The maximum number of cases belonged to the age groups of 21 to 40 years of age (83\%). In the present study around $57 \%$ of the patients with Fibroadenoma were observed in 11 to 30 years of age group. In the present study, Cyclical Mastalgia with nodularity mainly presented in 21 to 40 years of age group. Incapacitating mastalgia mainly presented in 31 to 40 years of age group. The main age group of presentation of Duct ectasia is 31 to 40 years. Giant fibroadenoma presented between 21 to 40 years of age group. Majority of cases were in reproductive age group with other complaints such as irregular menses, significant family history and significant increase in pain and size of the swelling in relation to the menstrual cycle. In my present study, majority of the study population presented with Fibroadenoma (60\%), followed by Cyclical mastalgia with nodularity (30\%), Incapacitating mastalgia (5\%), Duct ectasia (3\%) and Giant Fibroadenoma (2\%) in rest of the cases. The main age group of presentation is 21 to 40 years of age group.

\section{Clinical Presentation}

In the present study, the most common symptom is painless lump which constitutes about $50 \%$ of cases. Around $40 \%$ of cases presented with painful lumps and lumpiness (if no distinct lumps are not made out). The pain is predominately dull aching, pricking either with in the lump or all over the breast. In total 60 cases of Fibroadenoma, 50 cases presented with painless lump and 10 cases presented with painful lumps. In total 30 cases of cyclical mastalgia with nodularity, almost all the cases presented with painful lumps or indistinct nodularity. The cases of Duct ectasia with nodularity presented as nipple discharge with painful lumps (3\%) and Giant Fibroadenoma presented with painless lumps (2\%).

\section{Site of Lesion}

In the present study, out of 100 cases, $36 \%$ of cases had the disease manifested in right breast and $29 \%$ of cases in left breast and $35 \%$ of cases in both the breasts. It showed that majority of the breast conditions are seen in right breast followed by left breast. Majority of the cases of fibroadenoma presented in right breast (34\%) and followed by left breast $(25 \%)$ and in both the breasts $(1 \%)$ in rest of the cases. Nearly most of the cases of cyclical mastalgia with nodularity presented in both the breasts and only one case among the rest presented in the left breast. All the cases of incapacitating mastalgia presented in both the breasts. Two cases of Duct ectasia presented in right breast and one case in left breast. All the cases of Giant fibroadenoma are presented in the left breast. Majority of the cases had lesion in the Upper and outer quadrant of the breast. In the cases of Fibroadenoma, out of 60 cases 36 cases are present in upper and outer quadrant of the breast followed by 26 cases in upper inner and 15 cases in outer lower quadrants of the breast. 38 cases occupied more than two quadrants. Out of 30 cases of Cyclical Mastalgia with nodularity 19 cases presented in upper and outer quadrant of breast, 13 cases in lower and inner quadrant and 9 cases in upper and inner quadrant. 28 cases showed distribution in more than two quadrants. Giant fibroadenoma occupied more than two quadrants i.e; upper outer and inner and upper inner quadrants. Incapacitating mastalgia and Duct ectasia presented with diffuse pain all over the breast and was never localised to a quadrant.

\section{Investigations}

Fine Needle Aspiration Cytology (FNAC) was done for 62 cases in the present study and it was conclusive in all the cases $(100 \%)$. FNAC is advised only in clinically diagnosed cases of Fibroadenoma, and it was confirmed in histopathology of the excised specimen.

\section{Management}

Patients were managed either surgically or medically depending on the condition. Out of 100 cases 60 patients needed surgery and majority of the cases were under the disease - Fibroadenoma. Out of 60 cases of Fibroadenoma 55 cases underwent surgery and 5 cases were managed conservatively. The most commonly done surgery was excision of the lump. The incisions are given in radial and circum-areolar manner depending on the location of the lump. The excised samples are sent for histopathological examination. Medical management included analgesics and centchroman capsules and flax seeds. All the cases of Duct ectasia underwent microdochectomy and Giant fibroadenoma underwent excision. Suction drain was placed whenever necessary and was removed after 48 hours. Post-operative antibiotics and analgesics were given and sutures were removed on seventh post-operative day.

\section{CONCLUSIONS}

The most common presentation is lump in the breast, followed by pain in the breast. Majority of the benign breast diseases occur in young age group followed by middle age group. Fibroadenoma and mastalgia present as the most common disorders. Fibroadenoma usually presents as discrete lump in the breast but multiple lumps in one breast and lumps in both the breasts are also seen. Benign breast diseases most commonly affect upper and outer quadrant of the breast. Fine Needle Aspiration Cytology and Ultrasonogram nearly confirmed all the cases. Surgery proved to be the best way to manage the cases of fibroadenoma and simple excision was the better procedure.

\section{REFERENCES}

[1] Russel RCG, Norman WS, Christopher BJK. The Breast. Chap - 46. Bailey and Love's short practice of surgery. 23 $3^{\text {rd }}$ edn. London: Arnold Publishers 2000: p. 749-72.

[2] Md. Julie LR. Benign breast disease. In: Cameron JL, edr. Current surgical therapy. $6^{\text {th }}$ edn. Philadelphia: Mosby 1998: 624-6.

[3] Wagner FB Jr, Martin RG Sr, Kirby BI. History of the therapy of breast disease. Chap - 1. In: Kirby BI, Copeland 3rd, Ward M, eds. The breast comprehensive 
management of benign and malignant diseases. Vol. 1. $2^{\text {nd }}$ edn. Philadelphia: W.B. Saunders Company 1998: p. 1-18.

[4] Robert ME, Nell FJ, Eleri DL. Benign breast disease and its management. Chap - 5. In: Johnson CD, Taylor I, eds. Recent advances in surgery. No. 21. Edinburgh: Churchill Livingstone 1998: p. 71-3.

[5] Francis RE, Ernest RL. Examination techniques: roles of the physician and patient in evaluating breast diseases. Chap - 32. In: Kirby BI, Copeland 3rd EM, eds. The breast - comprehensive management of benign and malignant diseases. Vol. 1. $2^{\text {nd }}$ edn. Philadelphia: W.B Saunders Company 1998: p. 615-23.

[6] Haagensen CD. Adenosis tumour. Chap - 8. In: Haagensen CD, edr. Diseases of the breast. $2^{\text {nd }}$ edn. Philadelphia: W.B. Saunders Company 1971: p. 177-87.

[7] Mies C, Rosen PP. Juvenile fibroadenoma with atypical epithelial hyperplasia. AM J Surg Pathol 1987;11(3):18490.

[8] Brodie B. Lecture on Serocystic tumours of the breast. London Medical Gazette 1840;25:808.

[9] Haagensen CD. Disease of the breast. Philadelphia: W.B. Saunders 1971.

[10] Geschickter L. Disease of the breast. $2^{\text {nd }}$ edn. Philadelphia: JB Lippincott Company 1945.

[11] William DL. Common benign conditions of the breast. Chap - 7. In: William DL, John SS, eds. Cancer of the breast. $4^{\text {th }}$ edn. Philadelphia: W.B. Saunders Company 1995: p. 87-115.

[12] Hughes LE, Mansel RE, Webster DJT. Fibroadenoma and related tumours. Benign disorders and diseases of the breast concepts and clinical management. London: Bailliere Tindall Ltd., 1989: p. 59-74.

[13] Foster ME, Garrahan N, Williams S. Fibroadenoma of the breast: a clinical and pathological study. Journal of the Royal College of Surgeons of Edinburgh 1988;33(1):16-9.

[14] Haagensen CD. Adenofibroma of the Breast. Chapter - 12. In: Haagensen CD, edr. Diseases of the breast. $2^{\text {nd }}$ edn. Philadeplphia: W.B. Saunders Company 1971: p. 212-26.

[15] Haagensen CD. Cystosarcoma Phyllodes. Chapter - 13. In: Haagensen CD, edr. Diseases of the Breast. $2^{\text {nd }}$ edn. Philadelphia: W.B. Saunders Company 1971: p. 227-49.

[16] Mansel RE, Singal H. Developmental abnormalities and benign breast disease. Chap - 7. In: Farndon JR, edr. Breast and endocrine surgery. London: W.B. Saunders Company 1997: p. 197.

[17] Hughes LE, Mansel RE, Webster DJ. Aberrations of normal development and involution (ANDI): a new perspective on pathogenesis and nomenclature of human breast disorders. Lancet 1987;2(8571):1316-19.

[18] Haagensen CD. Non-epithelial Neoplasms of the Breast. Chap - 15. In: Haagensen CD, edr. Diseases of the Breast. $2^{\text {nd }}$ edn. Philadelphia: W.B. Saunders Company 1971: p. 292-325.

[19] Haagensen CD. Tumours of the skin and the accessory glands of the skin. Chap - 16. In: Haagensen CD, edr. Diseases of the Breast. $2^{\text {nd }}$ edn. Philadelphia: W.B. Saunders Company 1971: p. 326-32.

[20] Elston CW, Ellis IO. Fibroadenoma and related conditions. Chap - 9. In: Elston CW, Ellis IO, eds. Symmer's systemic pathology: the breast. Vol. 13. $3^{\text {rd }}$ edn. Edinburgh: Churchill Livingstone 1998: p. 147-86.
[21] Mansel RE, Wisbey JR, Hughes LE. Controlled trail of the antigonadotrophin Danazol in painful nodular benign breast disease. Lancet 1982;319(8278):928-30.

[22] Fentiman IS, Caleffi M, Hamed $H$, et al. Dosage and duration of tamoxifen treatment for mastalgia: a controlled trial. British Journal of Surgery 1988;75(9):845-6.

[23] Cant PJ, Madden MV, Coleman MG, et al. Non-operative management of breast masses diagnosed as fibroadenoma. British Journal of Surgery 1995;82(6):792-4.

[24] Scholefield JH, Duncan JL, Rogers K. Review of hospital experience of breast abscesses. British Journal of Surgery 1987;74(6):469-70.

[25] Fechner RE. Fibroadenoma and related lesions. In: Page DL, Anderson TJ, eds. Diagnostic histopathology of the breast. New York: Churchill Livingstone 1987: p. 72-85.

[26] Wechselberger G, Schoeller T, Piza-Katzer H. Juvenile fibroadenoma of the breast. Surgery 2002;132(1):106-7.

[27] Maddox PR, Harrison BJ, Mansel RE, et al. Non- cyclical mastalgia: an improved classification and treatment. British Journal of Surgery 1989;76(9):901-4.

[28] Ozzello L, Gump FE. The management of patients with carcinomas in fibroadenomatous tumours of the breast. Surg Gynecol Obstet 1985;160(2):99-104.

[29] Dupont WD, Page DL. Risk factors for breast cancer in women with proliferative breast disease. New Engl J Med 1985;312(3):146-51.

[30] Oberman HA. Breast lesions in the adolescent female. Pathol Annu 1979;14 Pt 1:175-201.

[31] Durning P, Sellwood RA. Bromocriptine in severe cyclical breast pain. British Journal of Surgery 1982;69(5):248-9.

[32] Lawrence BW. Breast imaging. Chapter - 35. In: Kirby BI, Copeland EM 3rd, eds. The breast - comprehensive management of benign and malignant diseases. Vol. 1. $2^{\text {nd }}$ edn. Philadelphia: W.B. Saunders Company 1998: p. 64897.

[33] Kirby BI, Copeland EM 3rd. Management of benign and malignant diseases. Vol. 1. $2^{\text {nd }}$ edn. Philadelphia: W.B. Saunders Company 1998: p. 233-46.

[34] Dodd GD. Present status of thermography, ultrasound and mammography in breast cancer detection. Cancer 1977;39(Suppl 6):2796-805.

[35] Helvie MA, Chang HP, Adler DD, et al. Breast thickness in routine mammograms: effect on image quality and radiation dose. AJR AM J Roentgenol 1994;163(6):13714.

[36] Love SM, Schmitt SJ, Connolly JL, et al. Benign breast disorders. Philadelphia: JB Lippincott Company 1987: p. 15-53.

[37] Lester SC, Cotran RS. The Breast. Chap - 25. In: Cotran RS, Vinaykumar, Collins T, eds. Robbins pathologic bases of diseases. Noida: W.B. Saunders Company 1999: p. 1093.

[38] Pike AM, Oberman HA. Juvenile (Cellular) adenofibromas. A clinicopathologic study. AM J Surg Pathol 1985;9(10):730-6.

[39] Tavassoli FA. Biphasic tumours. In: Tavassoli FA, edr. Pathology of the breast. Norwalk: Appleton and Lange Publisher 1992: p. 425-81. 
[40] Hadfield GJ. Benign disease of breast. In: Hadfield GJ, Hobsley M, eds. Current surgical practice. Vol. 1. London: Edward Arnold 1976.

[41] Page DL, Anderson TJ. Papilloma and related lesions. In: Diagnostic histopathology of the breast. New York: Churchill Livingstone 1987: p. 104-19.

[42] Eric FR, Kirby BI. Evolution of surgical principles and techniques for the management of breast cancer. Chap -
39. In: Kirby BI, Copeland EM 3rd, eds. The breast comprehensive management of benign and malignant disease. Vol. 2. $2^{\text {nd }}$ edn. Philadelphia: W.B. Saunders Company 1998: p. 766-801.

[43] Susheela K, Aryya NC, Khanna NN. Spectrum of benign breast disease. Indian Journal of Surgery 1998;50:169-75. 